\title{
Temperature dependence of density and viscosity of vegetable oils
}

\author{
Bernat Esteban, Jordi-Roger Riba*, Grau Baquero, Antoni Rius, Rita Puig \\ Escola d'Enginyeria d'Igualada (EEI-Escola d'Adoberia), Universitat Politècnica de Catalunya, Plaça del Rei 15, 08700 Igualada, \\ Catalunya, Spain
}

\section{A R T I C L E I N F O}

\section{Article history:}

Received 28 January 2011

Received in revised form

27 January 2012

Accepted 14 March 2012

Available online 5 April 2012

\section{Keywords:}

Viscosity

Density

Straight vegetable oil

Diesel engine

Combustion

\begin{abstract}
A B S T R A C T
The straight use of vegetable oils as fuel in diesel engines entails adjusting several physical properties such as density and viscosity. By adequately heating the vegetable oil before entering the injection system, its physical parameters can reach values very close to that of diesel fuel. Consequently, by properly adjusting the temperature of vegetable oils used as fuel, it is possible to improve their combustion performance, thus avoiding premature engine aging due to incomplete burning. In this study the density and viscosity of several vegetable oils are studied within a wide variety of temperatures. The optimal range of temperatures at which each vegetable oil should operate in order to adjust its properties to those of automotive diesel and biodiesel is then found. Additionally an empirical relationship between the dependence of viscosity with density is presented. Thus, by means of the above-described relationship, through measuring the density of a given oil, its viscosity can be directly deduced.
\end{abstract}

() 2012 Elsevier Ltd. All rights reserved.

\section{Introduction}

Diesel engines are being extensively utilized worldwide due to their high economic advantage and durability [1,2]. They have appealing features including robustness, high torque, and lower fuel consumption under certain conditions. According to Moron et al. [3] they are prevalent in sectors such as road and train transport, agriculture, military, construction, mining, maritime propulsion and stationary electricity production. Diesel engines can use several fuel types, including diesel fuel, straight vegetable oils (SVO), biodiesel transesterified vegetable oil - and short chain alcohols. Diesel engines may also function with hybrid fuels, including SVO mixtures in different proportions with diesel or diesel/ ethanol.

At the present time there is an increasing demand for energy, concerns about global warming and a growing interest in renewable energy sources; particularly in biofuels [4,5]. This is due to diminishing reserves and price instability of the world's petroleum fuel. These challenges are in part due to the diesel engines themselves. Consequently, it is an urgent matter to reduce hazardous pollutants that diesel engines emit such as $\mathrm{NO}_{\mathrm{x}}, \mathrm{CO}, \mathrm{CO}_{2}$ and particulate matter (PM). According to Lee at al. [1] this can be achieved by using new combustion technology, by improving fuel characteristics and or by applying after-treatment technology. It is well known that utilizing biofuels with internal combustion engines may contribute to reduce greenhouse gas emissions [6]. Smallscale produced SVOs are considered attractive options for renewable fuel because of environmental benefits [7]. Smallscale use of vegetable oils is also considered an interesting option because they can be obtained from agricultural or industrial sources with very simple processing. This processing includes cold pressing and refining stages that avoid

\footnotetext{
* Corresponding author. Tel.: +34 938035300; fax: +34 938031589.

E-mail address: jordi.riba@eei.upc.edu (J.-R. Riba). 
chemicals and complex processes involved in biodiesel production. To summarize, the straight use of vegetable oils in diesel engines avoids the transesterification stage required to obtain biodiesel, lowering energy consumption and reducing considerably environmental impacts due to lower polluting emissions and less chemicals consumption [7].

There are some similarities between most available vegetable oils and diesel fuel, making the vegetable oils appealing to be used as fuel. For example, the lower heating values (LHVs) of vegetable oils are very close to that of diesel fuel [8]. However, some physical and chemical differences exist. For example, the cetane number is a variable that affects the ignition quality and therefore determines the flammability of the fuel [9]. Diesel fuel has higher cetane number than vegetable oils, implying a shorter ignition delay [10] and a small change in engine efficiency [11]. However, the difference in ignition delay between diesel fuel and SVOs is not significant [9] and may be compensated by adjusting the ignition delay [12]. It is an accepted fact that viscosity has a significant effect on spray characteristics. Higher viscosity leads to: inferior fuel atomization, higher Sauter mean diameter -the ratio of the mean volume to the mean surface of the fuel droplets- and lower spray speed than conventional diesel fuel [13-16]. The atomization effectiveness depends on the geometry of the injection system, various fuel properties such as viscosity, surface tension and density [3,17]. SVO viscosity has a profound effect on the flow through the fuel system, thus influencing how the oil sprays from the injector.

It is also an accepted fact that the large molecular sizes of the triglycerides contained in vegetable oils results in higher viscosity, higher density and lower volatility compared to diesel fuel. That, in turn, causes poor fuel atomization due in part to the large size of droplets upon injection into the cylinder and also due to high-spray jet penetration. Optimal atomization improves mixing and complete combustion in diesel engines, which has great impact on emissions and efficiency [18]. Higher viscosity fuels cause the jet to become a solid steam instead of a spray composed of small droplets [19] resulting in poor combustion that produces black smoke and provokes the development of deposits in the combustion chamber. Furthermore, the introduction of unburnt fuel, which flows down the cylinder wall into the crankcase, dilutes the vegetable oil in the lubrication engine oil [20]. Higher viscous fuels tend to form larger droplet size, which fosters other competitive reactions, such as charring or coking and polymerization. Contrarily, as pointed out by Nwafor et al. [20], viscous fuels have a higher lubricating effectiveness. It is recognized that indirect injection engines are less affected by viscosity differences than direct injection engines [21,22].

Observations gathered using SVO as fuel in unmodified diesel engines draw attention to the need to fit the most relevant physical properties, which narrows this study to density and viscosity [23]. When using SVO as fuel in an unmodified diesel engine, its viscosity has to be lowered to allow appropriate atomization. If not, incomplete SVO combustion and carbonization will eventually damage the engine. Consequently, when using SVO in these engines, some precautions must be taken. Often, vegetable oils are preheated to reach appropriate density and viscosity values before reaching the injectors by using a heater. Once heated,
SVO becomes very similar to diesel fuel in terms of physical properties, which will be discussed further in this study.

Several studies have been carried out that focus on lowering the viscosity of vegetable oils by appropriate heating. One of the earliest studies was carried out by Murayama et al. [24] who suggested increasing the temperature of rapeseed oil to $200{ }^{\circ} \mathrm{C}$ to achieve efficient combustion for direct injection diesel engines. More recently, Agarwal et al. [25] found that heating the Jatropha oil between $90{ }^{\circ} \mathrm{C}$ and $100{ }^{\circ} \mathrm{C}$ before combustion in a diesel engine was adequate to lower the viscosity within a close range to diesel. Moreover this study concluded that preheating the Jatropha oil does not lead to change in optimum fuel injection pressure. Additionally, some of the available commercial kits applied to use SVO in automotive diesel engines utilize a heat exchanger to raise the temperature of vegetable oil. These kits frequently use the water of the cooling circuit to heat the SVO up to about $70-80^{\circ} \mathrm{C}$. All of this information makes it clear that there is discrepancy in the data concerning the optimal temperature at which each particular SVO should be preheated in order to obtain improved combustion.

Although density and even more so viscosity play an important role in the evaluation of fuel performance, there is very little published information about the optimal temperature level at which the SVOs have improved performance in diesel engines. Hence, it would be extremely beneficial to know the values of these properties within the vast range of temperatures to find out the most appropriate heating temperature for each one of the analyzed vegetable oils.

The aim of this paper is to obtain insightful knowledge about the temperature dependencies of the critical physical parameters, such as density and viscosity of commonly used vegetable oils, including rapeseed, sunflower, soybean, palm, corn and grapeseed. This includes the most significant vegetable oils produced worldwide during 2009, i.e. palm, soybean, rapeseed and sunflower [26]. The results presented in this study will allow adjusting the density and viscosity values of the vegetable oils with that of other fuels currently being used in diesel engines. Mathematical expressions of temperature dependences of these physical parameters are given to characterize the vegetable oils studied. Additionally, the densities and viscosities of the vegetable oils analyzed are compared with those of commercial pure biodiesel and automotive diesel fuel in order to compare their physical parameters. From this comparison and from the limit values proposed in Section 2.2, the heating temperature to match the density and viscosity values of automotive diesel and biodiesel is obtained.

In order to characterize the vegetable oils and pure biodiesel samples used in this study, their composition has been analyzed by means of gas chromatography. Table 1 gives a listing of the samples analyzed in this paper. Their fatty acid composition is given in mass percent.

\section{Methodology}

\subsection{Temperature dependence of density and viscosity}

As discussed in the introduction, density and viscosity play an important role in the atomization process, which in turn 
Table 1 - Fatty acid composition of the analyzed vegetable oils.

\begin{tabular}{|c|c|c|c|c|c|c|c|c|}
\hline Carbon number & Systematic name (common) & Rapeseed & Sunflower & Soybean & Palm & Corn & Grapeseed & Biodiesel \\
\hline C12:0 & Dodecanoic (lauric) & - & - & - & $0.1 \%$ & - & - & - \\
\hline C14:0 & Tetradecanoic (myristic & $<0.1 \%$ & $<0.1 \%$ & $<0.1 \%$ & $0.9 \%$ & $<0.1 \%$ & $<0.1 \%$ & $0.3 \%$ \\
\hline C16:0 & Hexadecanoic (palmitic) & $4.7 \%$ & $6.7 \%$ & $11.2 \%$ & $45.6 \%$ & $11.4 \%$ & $7.2 \%$ & $18.6 \%$ \\
\hline C16:1 & Hexadecenoic (palmitoleic) & $0.3 \%$ & $0.3 \%$ & $0.2 \%$ & $0.4 \%$ & $0.3 \%$ & $0.1 \%$ & $0.8 \%$ \\
\hline $\mathrm{C} 18: 0$ & Octadecanoic (estearic) & $1.3 \%$ & $2.9 \%$ & $2.9 \%$ & $3.8 \%$ & $1.7 \%$ & $3.9 \%$ & $4.5 \%$ \\
\hline C18:1 & Octadecenoic (oleic) & $65.3 \%$ & $38.7 \%$ & $25.2 \%$ & $38.5 \%$ & $32.8 \%$ & $20.2 \%$ & $32.0 \%$ \\
\hline C18:2 & Octadecadienoic (linoleic) & $19.2 \%$ & $51.3 \%$ & $55.4 \%$ & $10.5 \%$ & $53.3 \%$ & $68.4 \%$ & $39.7 \%$ \\
\hline C18:3 & Octadecatrienoic (linolenic) & $8.3 \%$ & $<0.1 \%$ & $5.0 \%$ & $0.1 \%$ & $0.5 \%$ & $0.2 \%$ & $4.0 \%$ \\
\hline C20:1 & Eicosenoic (gadoleic) & $0.7 \%$ & $<0.1 \%$ & $0.1 \%$ & - & $<0.1 \%$ & $<0.1 \%$ & - \\
\hline C22:1 & Docosenoic (erucic) & $<0.3 \%$ & - & - & - & - & - & - \\
\hline
\end{tabular}

determines if complete combustion is carried out in a diesel engine which consequently influences engine emissions and efficiency. Therefore, in order to achieve the correct fuel atomization, proper values of density and viscosity are required. Moreover, both, density and viscosity are highly temperature sensitive. In this section these dependences are analyzed and mathematical equations to set them are explained.

\subsubsection{Density}

Density is an important physical characteristic of any substance, and is a measure of the mass per unit of volume of that substance. It is an accepted fact that vegetable oil density decreases linearly with increasing temperature. This relationship can be expressed mathematically as [27],

$\rho=a+b \cdot T$

where $\rho$ is the density expressed in $\mathrm{g} \mathrm{cm}^{-3}, \mathrm{~T}$ is the temperature expressed in ${ }^{\circ} \mathrm{C}, a$ is the intercept and $b$ is a negative slope.

\subsubsection{Viscosity}

Viscosity is a measure of the resistance offered by a fluid to flow. According to Krisnangkura et al. [28] viscosity may be considered the integral of the interaction forces of molecules. When heat is applied to fluids, molecules can then slide over each other more easily making the liquid to become less viscous. The effect of temperature on the kinematic viscosity of liquid is described by means of the Arrenhius equation as,

$\eta=\mathrm{A}_{1} \cdot \exp ^{\frac{E_{a}}{\mathrm{RT}}}$

$\eta$ being the kinematic viscosity, $E_{a}$ the activation energy for flow, $R$ the universal gas constant and $T$ the absolute temperature. Additionally, $A_{1}=N_{A} h / V$, where $N_{A}, V$ and $h$ are the Avogadro's number, the molecular volume and the Plank's constants, respectively. The SI physical unit of kinematic viscosity is $\mathrm{m}^{2} \mathrm{~s}^{-1}$.

In the case of vegetable oils, Equation (2) can be rewritten as in Equation (3) which is known as the Andrade equation $[27,28]$

$\eta=\mathrm{A}_{1} \cdot \exp ^{\mathrm{B} / \mathrm{T}}$

where $T$ is the absolute temperature and $A_{1}$ and $B$ are specific constants to be adjusted for each specific oil. By applying logarithms to both sides of Equation (3) it leads to,

$\ln (\eta)=A+B / T$
Equation (4) allows us to linearize the Equation (3) by applying the least-squares method and making $1 / T$ the independent variable. Additionally, Azian et al. [29] suggested modifying the Equation (4), which is especially useful when dealing with wide temperature ranges,

$\ln (\eta)=\mathrm{A}+\mathrm{B} / \mathrm{T}+\mathrm{C} / \mathrm{T}^{2}$

Sometimes, the dynamic or absolute viscosity $\mu$ is applied, which can be calculated from the kinematic viscosity $\eta$ and the density $\rho$ as,

$\mu=\eta \cdot \rho$

The SI physical unit of dynamic viscosity is the $\mathrm{Pa}$, which is identical to $\mathrm{kg} \mathrm{m}^{-1} \mathrm{~s}^{-1}$.

\subsubsection{Interdependence between viscosity and density}

As both, density and viscosity are highly temperature sensitive, it is possible to find out the dependence between them. This dependence is often used in the oil industry [30]. The measurement of density is very simple and quick because it requires a low-cost hydrometer that is quite easy to use. On the other hand, the measurement of the viscosity is more complex and time consuming, requiring a more complex and expensive assessment instrument employed by qualified laboratory technicians. If the relationship between density and viscosity is known, one only needs to measure the density of a given oil to deduce its viscosity. According to Rodenbush et al. [27], when dealing with vegetable oils the dependence between density and viscosity can be expressed as illustrated in Equation (7).

$\rho=\mathrm{D}+\mathrm{E} / \eta^{1 / 2}$

Equation (7) is particularly useful because it can be adjusted by means of a least-squares linear regression by choosing $1 / \eta^{1 / 2}$ as an independent variable.

\begin{tabular}{|c|c|c|c|}
\hline \multirow[t]{2}{*}{ Standard } & \multirow[t]{2}{*}{ Fuel } & \multicolumn{2}{|c|}{ Density $\left(\mathrm{g} \mathrm{cm}^{-3}\right)$ Viscosity $\left(\mathrm{mm}^{2} \mathrm{~s}^{-1}\right)$} \\
\hline & & $15^{\circ} \mathrm{C}$ & $40^{\circ} \mathrm{C}$ \\
\hline EN 590 & Diesel fuel & $0.820-0.845$ & $2.00-4.50$ \\
\hline EN 14214 & Biodiesel & $0.860-0.900$ & $3.50-5.00$ \\
\hline DIN 51605 & Rapeseed oil & $0.910-0.925$ & Max. 36.00 \\
\hline
\end{tabular}




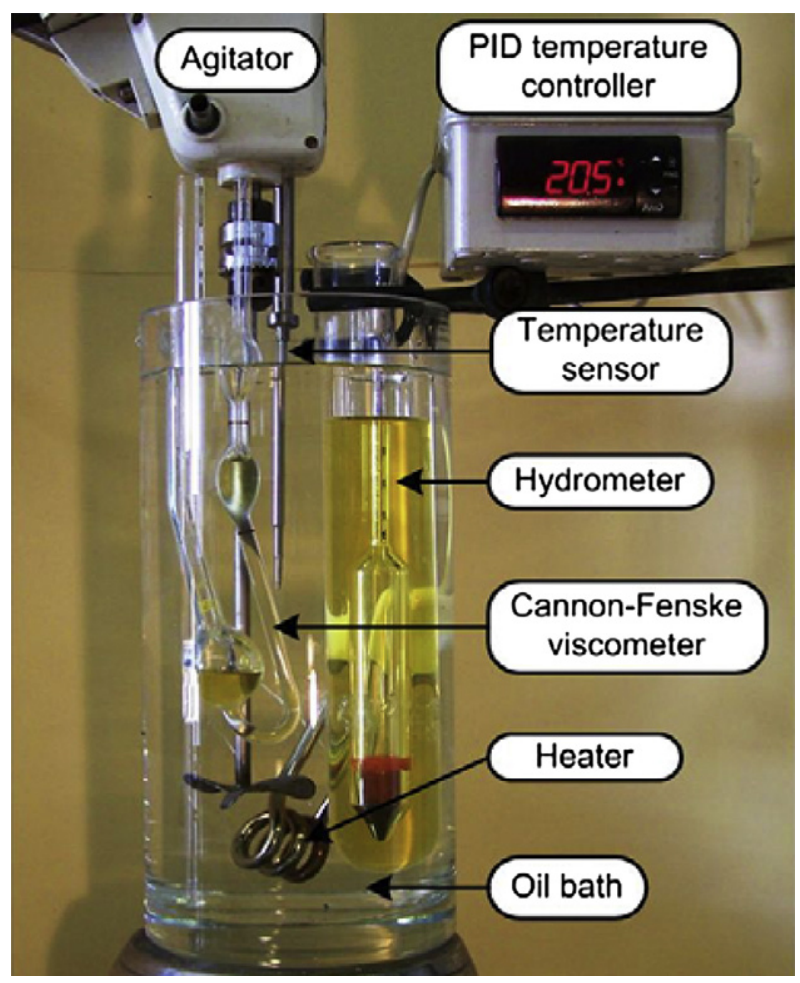

Fig. 1 - Experimental setup used to measure the density and viscosity of vegetable oils in the temperature range $10^{\circ} \mathrm{C}-140{ }^{\circ} \mathrm{C}$.

\subsection{Density and viscosity ceiling values}

In this section different European standards regarding the density and viscosity requirements of various automotive fuels sold in the European Union are examined. The European standards analyzed are EN 590:2004 [31] which pertains to automotive diesel fuel and EN 14214:2008 [32] that is associated with biodiesel. The German norm DIN 51605 [33] concerning the straight use of rapeseed oil in diesel engines is also included in this comparison. Table 2 summarizes the limit values of density and viscosity for diesel fuel, pure biodiesel and rapeseed oil agreed upon by these European standards.

Concerning the performance of diesel engines, it is acknowledged that the effects of using vegetable oils greatly depend on the engine sensitivity to fuel injection and on the combustion characteristics of the vegetable oil $[34,35]$. Current diesel engines have fuel injection systems that are susceptible to viscosity changes [36]. According to Totten et al. [19], the recommended viscosity values for diesel engine fuels range from 1.8 to $5.8 \mathrm{~mm}^{2} \mathrm{~s}^{-1}$ at $38{ }^{\circ} \mathrm{C}$. The lower viscosity limit is imposed to provide adequate lubrication for injection system components and to prevent leakage. More recently, Mohamed Y.E. Selim [18] recommended a range lying between 1.6 and $7 \mathrm{~mm}^{2} \mathrm{~s}^{-1}$ when operating at $40^{\circ} \mathrm{C}$. Thus, viscosity limit values imposed by EN 590:2004 and EN 14214:2009 [31,32] are compatible with viscosity values close to $5.8 \mathrm{~mm}^{2} \mathrm{~s}^{-1}$. This value is recommended in [19], and the range $1.6-7 \mathrm{~mm}^{2} \mathrm{~s}^{-1}$ is suggested in [18]. Consequently, as deduced from technical literature, viscosity of vegetable oils should be lowered at least to values close to $6 \mathrm{~mm}^{2} \mathrm{~s}^{-1}$ when used as fuel in diesel engines to match the values of the European standards, thus avoiding the problems related to higher viscosity fuels. Additionally, from the abovementioned standards a conservative density value for SVO of $0.860 \mathrm{~g} \mathrm{~cm}^{-3}$ is proposed as a ceiling value because it meets the well accepted EN 14214:2008 [32] standard for biodiesel.

\section{Experimental}

In this study samples of different types of refined vegetable oils were analyzed including rapeseed, sunflower, soybean, palm, corn and grapeseed. Pure commercial biodiesel (BD100) and automotive diesel fuel were also included in the sampling. The vegetable oils samples were purchased from different local suppliers, whereas the biodiesel and automotive diesel samples were acquired from local petrol stations.

Table 3 - Dependence of density with temperature for automotive diesel fuel, pure biodiesel and the analyzed vegetable oils. SVO density values below $0.860 \mathrm{~g} \mathrm{~cm}^{-3}$ are in bold.

\begin{tabular}{|c|c|c|c|c|c|c|c|c|}
\hline \multirow[t]{2}{*}{ Temp. $\left({ }^{\circ} \mathrm{C}\right)$} & \multicolumn{8}{|c|}{ Density $\left(\mathrm{g} \mathrm{cm}^{-3}\right)$} \\
\hline & Diesel & BD100 & Rapeseed & Sunflower & Soybean & Palm & Corn & Grapeseed \\
\hline 10 & 0.8376 & 0.8859 & 0.9210 & 0.9251 & 0.9254 & - & 0.9237 & 0.9259 \\
\hline 20 & 0.8308 & 0.8798 & 0.9145 & 0.9169 & 0.9185 & - & 0.9167 & 0.9188 \\
\hline 30 & 0.8242 & 0.8717 & 0.9080 & 0.9114 & 0.9127 & - & 0.9113 & 0.9126 \\
\hline 40 & 0.8181 & 0.8641 & 0.9027 & 0.9043 & 0.9061 & 0.8996 & 0.9046 & 0.9060 \\
\hline 50 & 0.8114 & 0.8583 & 0.8963 & 0.8994 & 0.8998 & 0.8922 & 0.8979 & 0.8998 \\
\hline 60 & 0.8043 & 0.8513 & 0.8911 & 0.8926 & 0.8941 & 0.8845 & 0.8920 & 0.8941 \\
\hline 70 & 0.7970 & 0.8433 & 0.8848 & 0.8877 & 0.8879 & 0.8789 & 0.8864 & 0.8874 \\
\hline 80 & 0.7890 & 0.8372 & 0.8777 & 0.8798 & 0.8817 & 0.8721 & 0.8801 & 0.8813 \\
\hline 90 & 0.7825 & 0.8287 & 0.8724 & 0.8743 & 0.8750 & 0.8664 & 0.8740 & 0.8754 \\
\hline 100 & 0.7759 & 0.8229 & 0.8658 & 0.8670 & 0.8689 & 0.8595 & 0.8678 & 0.8695 \\
\hline 110 & 0.7708 & 0.8150 & 0.8593 & 0.8602 & 0.8626 & 0.8536 & 0.8610 & 0.8626 \\
\hline 120 & 0.7636 & 0.8075 & 0.8537 & 0.8536 & 0.8566 & 0.8457 & 0.8555 & 0.8570 \\
\hline 130 & 0.7577 & 0.8002 & 0.8469 & 0.8472 & 0.8498 & 0.8407 & 0.8489 & 0.8505 \\
\hline 140 & 0.7516 & 0.7912 & 0.8395 & 0.8408 & 0.8430 & 0.8325 & 0.8424 & 0.8440 \\
\hline
\end{tabular}


Table 4 - Main parameters of the density-temperature fit.

\begin{tabular}{lccccc} 
Sample & $a$ & $b\left(\times 10^{-4}\right)$ & $r^{2}$ & $F_{\text {calc }}\left(\times 10^{4}\right)$ & $F_{\text {tab }}$ \\
\hline Diesel fuel & 0.8442 & -6.7009 & 0.99911 & 1.3466 & 4.7472 \\
Biodiesel & 0.8938 & -7.2073 & 0.99932 & 1.7554 & 4.7472 \\
Rapeseed & 0.9273 & -6.1837 & 0.99945 & 2.1884 & 4.7472 \\
Sunflower & 0.9310 & -6.4145 & 0.99920 & 1.4907 & 4.7472 \\
Soybean & 0.9315 & -6.2790 & 0.99985 & 8.0160 & 4.7472 \\
Palm $^{2}$ & 0.9250 & -6.5612 & 0.99900 & 9.0182 & 5.1174 \\
Corn & 0.9295 & -6.2053 & 0.99983 & 6.9725 & 4.7472 \\
Grapeseed & 0.9314 & -6.2343 & 0.99982 & 6.7749 & 4.7472 \\
\hline
\end{tabular}

a Analysis done for $\mathrm{T} \geq 40^{\circ} \mathrm{C}$, as palm oil is solid below $40^{\circ} \mathrm{C}$.

A set of calibrated hydrometers with spans ranging from 0.7 to $0.95 \mathrm{~g} \mathrm{~cm}^{-3}$ were used to measure the density. The thermal expansion of glass has a slight influence on the hydrometer reading. To compensate this effect the temperature correction according to the standard ISO 649-2:1981 [37] has been applied.

Additionally, three Cannon-Fenske-type gravity flow viscometers series 50, 100 and 150 were utilized to measure the viscosity. They allowed measuring viscosity of all of the analyzed oils and fuels with flow times within the recommended range set by the standard ISO 3105:1994 [38]. The viscometers were calibrated by the manufacturer and the calibration constant $C_{0}(T)$ is supplied with the instrument. The viscosity is obtained from the following equation,

$\eta_{\text {app }}=\mathrm{t} \cdot \mathrm{C}_{0}(\mathrm{~T})$

$\eta$ being the kinematic viscosity in centistokes, $t$ the flow time expressed in seconds and $C_{0}(T)$ the characteristic calibration constant of each viscometer measured at the working temperature.

Additionally, to ensure precise and stable temperature control during measurements, a resistance temperature detector (RTD) was used to measure the temperature. The RTD was connected to a digital temperature PID controller. The controller allowed regulating the temperature of a heated oil bath containing the hydrometer and the viscometer by means of an electric heater. The temperature of the oil bath was adjusted from $10^{\circ} \mathrm{C}$ to $140^{\circ} \mathrm{C}$. Both, density and viscosity were measured within this temperature interval. Furthermore, the interdependence between density and viscosity was studied.

Each sample was tested three times, and the average density and viscosity were calculated. Fig. 1 shows the experimental setup used to determine the temperature dependence of density and viscosity of the samples analyzed.

\subsection{Density}

As stated, it is an accepted fact that fuel density has a great influence on the atomization process. Thus the knowledge of the temperature dependence of this parameter is a highly important component of the process of the study in order to ensure optimal combustion of the fuel [18].

The density of the different vegetable oils, pure biodiesel (BD100) and automotive diesel fuel samples were measured according to the method explained in Section 2.1.1. The set of measures carried out with in the range between $10{ }^{\circ} \mathrm{C}$ and $140^{\circ} \mathrm{C}$ is shown in Table 3.

Results presented in Table 3 clearly show that the density of diesel fuel is much lower than the density of the vegetable oils studied. However, heating any of the vegetable oils at a temperature of $120^{\circ} \mathrm{C}$ or higher is sufficient to ensure that density is below $0.860 \mathrm{~g} \mathrm{~cm}^{-3}$, corresponding to the inferior density limit given by the EN 14214:2008 European standard [32] for biodiesel fuel in diesel engines. Despite these observations, this temperature requirement can be lower depending on engine types and configurations. For example, in engines used in applications such as combined heat and power (CHP), vegetable oil may be injected at lower temperatures [39].

Table 4 shows a summary of the most relevant parameters related to the density-temperature fit obtained by applying Equation (1) when analyzing the whole set of samples. Once

Table 5 - Dependence of kinematic viscosity with temperature for automotive diesel fuel, pure biodiesel and the analyzed vegetable oils. SVO viscosity values below $6 \mathrm{~mm}^{2} \mathrm{~s}^{-1}$ are in bold.

Temp. $\left({ }^{\circ} \mathrm{C}\right)$ Kinematic viscosity $\left(\mathrm{mm}^{2} \mathrm{~s}^{-1}\right)$

\begin{tabular}{|c|c|c|c|c|c|c|c|c|}
\hline & Diesel & BD100 & Rapeseed & Sunflower & Soybean & Palm & Corn & Grapeseed \\
\hline 10 & 5.39 & 9.00 & 119.48 & 118.72 & 107.62 & - & 113.39 & 100.63 \\
\hline 20 & 4.15 & 6.78 & 74.19 & 73.45 & 67.12 & - & 70.29 & 64.32 \\
\hline 30 & 3.30 & 5.30 & 48.88 & 48.46 & 44.69 & - & 46.54 & 42.94 \\
\hline 40 & 2.70 & 4.26 & 34.06 & 33.78 & 31.42 & 45.34 & 32.53 & 30.19 \\
\hline 50 & 2.26 & 3.51 & 24.68 & 24.48 & 23.00 & 28.19 & 23.74 & 22.29 \\
\hline 60 & 1.92 & 2.94 & 18.62 & 18.52 & 17.47 & 20.84 & 17.96 & 17.04 \\
\hline 70 & 1.64 & 2.51 & 14.48 & 14.44 & 13.67 & 15.60 & 14.01 & 13.34 \\
\hline 80 & 1.43 & 2.16 & 11.58 & 11.53 & 11.17 & 12.35 & 11.39 & 10.88 \\
\hline 90 & 1.27 & 1.90 & 9.45 & 9.44 & 9.13 & 9.94 & 9.34 & 8.96 \\
\hline 100 & 1.14 & 1.69 & 7.89 & 7.78 & 7.71 & 8.21 & 7.83 & 7.53 \\
\hline 110 & 1.03 & 1.51 & 6.70 & 6.50 & 6.58 & 6.88 & 6.65 & 6.42 \\
\hline 120 & 0.93 & 1.36 & 5.86 & 5.62 & 5.68 & 5.85 & 5.70 & 5.49 \\
\hline 130 & 0.85 & 1.23 & 5.09 & 4.91 & 4.99 & 5.02 & 4.93 & 4.77 \\
\hline 140 & 0.78 & 1.13 & 4.47 & 4.37 & 4.45 & 4.38 & 4.34 & 4.21 \\
\hline
\end{tabular}




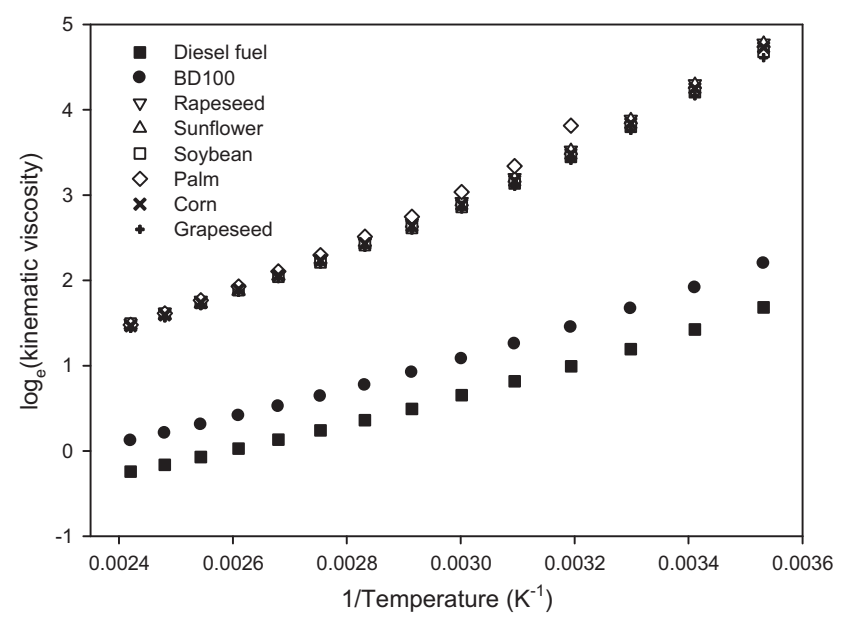

Fig. 2 - Dependence of $\log _{e}$ (kinematic viscosity) versus temperature ${ }^{-1}$ for automotive diesel fuel, pure biodiesel and the analyzed vegetable oils.

the experimental data have been adjusted by means of a statistical model it is highly recommended to establish a criterion to measure the goodness of a fit [40]. For this purpose the F-test was applied. Using this approach, the regression model is statistically significant to a fixed confidence level -usually set to $95 \%$ - if the following relationship is adhered to [41],

$F_{\text {calc }}>F_{\text {tab }}$

$F_{\text {tab }}$ being the tabulated value of the Fisher-Snedecor distribution with $\nu_{1}$ and $\nu_{2}$ degrees of freedom for a fixed significance level $1-\alpha$.

Results shown in Table 4 clearly indicate that the densitytemperature curves of the studied vegetable oils, diesel fuel and pure biodiesel can be adjusted by means of a straight line, resulting in significant statistics outcomes in all cases with a confidence level of $95 \%$. Additionally, high determination coefficients were obtained for the whole set of samples analyzed.

\subsection{Kinematic viscosity}

The kinematic viscosity is the other key factor to take into account in order to achieve optimal fuel atomization.
The kinematic viscosity of the different vegetable oils, pure biodiesel and diesel fuel were measured from $10^{\circ} \mathrm{C}$ to $140{ }^{\circ} \mathrm{C}$ according to the method explained in Section 2.1.2 and are shown in Table 5.

Table 5 shows that diesel fuel viscosity is quite inferior to the viscosity of the vegetable oils studied for the whole range of temperatures analyzed. It also indicates that for all analyzed vegetable oils, a temperature of $120^{\circ} \mathrm{C}$ is enough to ensure that viscosity is below $6 \mathrm{~mm}^{2} \mathrm{~s}^{-1}[18,19]$. As explained in Section 3.1, this ceiling value may be lower depending on the type of engine dealt with.

In order to characterize the temperature dependence of the kinematic viscosity, a least-squares linear fit should be performed according to Equation (5). The resulting dependencies are shown in Fig. 2.

Table 6 shows a summary of the most relevant parameters related to the $\log _{e}$ (viscosity)-temperature ${ }^{-1}$ fit obtained by applying Equation (5) when analyzing the whole set of samples.

Results shown in Fig. 2 and Table 6 indicate that Equation (5) is clearly fulfilled when dealing with the studied samples which in all cases obtained very high determination coefficients. Similar to other results, the outcomes were noteworthy with a confidence level of $95 \%$ for all the samples analyzed.

\subsection{Relationship between the kinematic viscosity and the density}

As explained in Section 2.1.3, it is valuable to have a mathematical expression linking density and viscosity of a given fuel or vegetable oil. Using this approach, by measuring the vegetable oil density, which is simple and fast, its viscosity can be estimated.

For characterizing the density-viscosity dependence, a least-squares linear fit should be carried out according to Equation (7), resulting in the dependencies shown in Fig. 3

From Fig. $3 b$ it is deduced that there exists a linear relationship between density and the inverse of the square root of the kinematic viscosity, as stated in Equation (7). Table 7 shows a summary of the most relevant parameters related to density-viscosity ${ }^{-1 / 2}$ fit obtained by means of Equation (7) for the whole set of samples analyzed.

Results shown in Fig. 3 and Table 7 indicate that Equation (7) is accomplished when dealing with the studied vegetable oils, diesel fuel and pure biodiesel obtained notably high $r^{2}$

Table 6 - Important parameters of the loge (kinematic viscosity) versus temperature-1 fit.

\begin{tabular}{|c|c|c|c|c|c|c|}
\hline Sample & A & B & C & $r^{2}$ & $F_{\text {calc }}\left(\times 10^{4}\right)$ & $F_{\text {tab }}$ \\
\hline Diesel fuel & -1.2202 & -499.62 & 373853.59 & 0.999949 & 23.3391 & 4.7472 \\
\hline Biodiesel & -0.8412 & -598.31 & 412410.30 & 0.999957 & 27.7126 & 4.7472 \\
\hline Rapeseed & 2.5315 & -2724.34 & 951274.72 & 0.999965 & 34.5676 & 4.7472 \\
\hline Sunflower & 1.9493 & -2358.16 & 893322.03 & 0.999928 & 16.6119 & 4.7472 \\
\hline Soybean & 2.7247 & -2801.29 & 948792.52 & 0.999929 & 16.9468 & 4.7472 \\
\hline Palm $^{\text {a }}$ & 4.5613 & -4444.00 & 1313500.49 & 0.998765 & 0.7277 & 5.1174 \\
\hline Corn & 2.1769 & -2469.25 & 902448.54 & 0.999838 & 7.3942 & 4.7472 \\
\hline Grapeseed & 1.7625 & -2154.47 & 837480.85 & 0.999856 & 8.3568 & 4.7472 \\
\hline
\end{tabular}

a Analysis done for $\mathrm{T} \geq 40^{\circ} \mathrm{C}$, as palm oil is solid below $40^{\circ} \mathrm{C}$. 
a

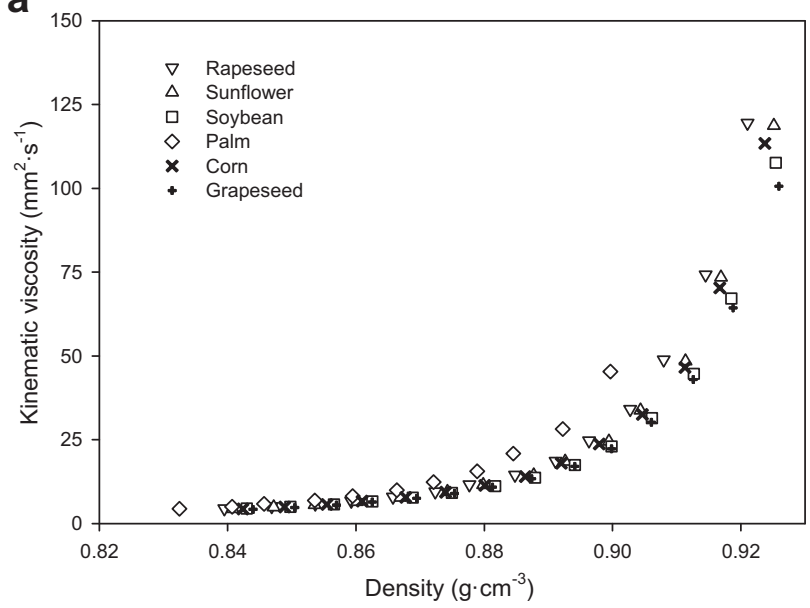

b

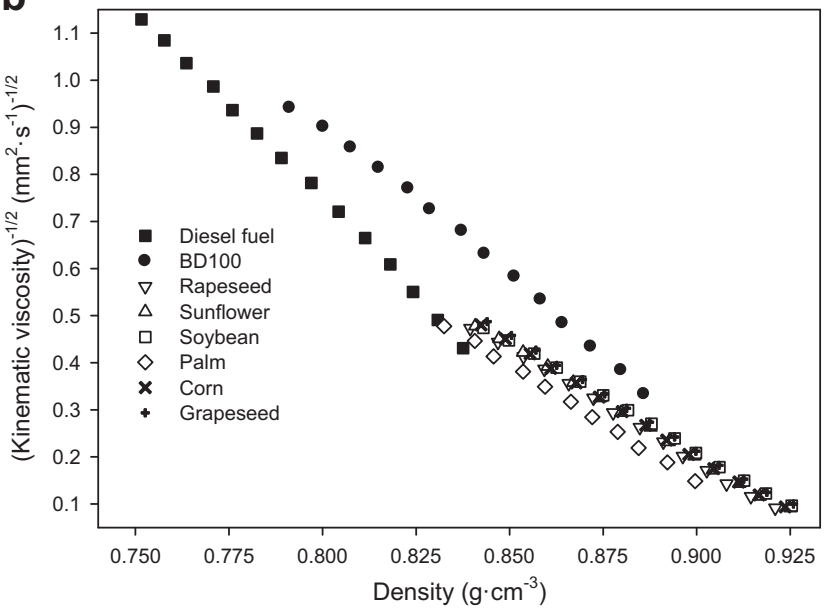

Fig. 3 - (a) Dependence of density with kinematic viscosity for the analyzed vegetable oils. (b) Dependence of density with (kinematic viscosity) ${ }^{-1 / 2}$ for automotive diesel fuel, pure biodiesel and the analyzed vegetable oils.

values in all cases. Additionally, results were quite favorable showing a confidence level of $95 \%$ for all the samples studied. Table 8 shows the prediction errors in the densityviscosity fit.

Results presented in Tables 7 and 8 indicate that for the analyzed samples a good estimation of the viscosity can be achieved from the measure of the density.

Table 7 - Important parameters of the density versus viscosity $^{-1 / 2}$ fit.

\begin{tabular}{lccccc} 
Sample & $D$ & $E$ & $r^{2}$ & $F_{\text {calc }}\left(\times 10^{4}\right)$ & $F_{\text {tab }}$ \\
\hline Diesel fuel & 7.1833 & -8.0456 & 0.9989 & 1.1331 & 4.7472 \\
Biodiesel & 6.1125 & -6.5067 & 0.9971 & 0.4123 & 4.7472 \\
Rapeseed & 4.5331 & -4.8285 & 0.9990 & 1.2986 & 4.7472 \\
Sunflower & 4.4707 & -4.7447 & 0.9988 & 0.9804 & 4.7472 \\
Soybean & 4.4546 & -4.7147 & 0.9993 & 1.8284 & 4.7472 \\
Palm ${ }^{a}$ & 4.6144 & -4.9634 & 0.9990 & 0.9283 & 5.1174 \\
Corn & 4.5604 & -4.8440 & 0.9993 & 1.8063 & 4.7472 \\
Grapeseed & 4.5744 & -4.8436 & 0.9991 & 1.3833 & 4.7472 \\
\hline a Analysis done for $\mathrm{T} \geq 40{ }^{\circ} \mathrm{C}$, as palm oil is solid below $40{ }^{\circ} \mathrm{C}$.
\end{tabular}

Table 8 - Error analysis of the density-viscosity fit for the analyzed samples.

\begin{tabular}{lccc} 
Error (\%) & Max. & Min. & Average \\
\hline Rapeseed & 7.62 & 0.24 & 2.33 \\
Sunflower & 8.41 & 0.03 & 2.46 \\
Soybean & 4.44 & 0.14 & 1.84 \\
Palm & 4.54 & 0.38 & 1.79 \\
Corn & 4.35 & 0.22 & 1.62 \\
Grapeseed & 5.27 & 0.10 & 1.40 \\
\hline
\end{tabular}

\section{Conclusion and discussion}

As mentioned, it is well known that both density and even more viscosity have a profound impact on the combustion efficiency of diesel engines, thus having a notable influence on their expected life.

In this study the temperature dependencies of density and viscosity of several commonly used vegetable oils, diesel fuel and pure biodiesel were measured and described by means of specific mathematical expressions. Furthermore, the densityviscosity dependence was analyzed, showing that a good estimation of the viscosity can be obtained from the measure of the density, which is a simple and time effective process.

Results of this research show that the analyzed vegetable oils require preheating to $120{ }^{\circ} \mathrm{C}$ minimally to match the studied physical properties of automotive diesel and biodiesel fuels. However, it is important to note that this temperature requirement depends on engine types and configurations.

\section{R E F E R E N C E S}

[1] Lee SW, Park S, Daisho Y. An experimental study of the effects of combustion systems and fuel properties on the performance of a diesel engine. Proc Inst Mech Eng D-J Auto Eng 2004;218:1317-23.

[2] Mbarawa M. The effect of clove oil and diesel fuel blends on the engine performance and exhaust emissions of a compression-ignition engine. Biomass Bioenergy 2010;34: 1555-61.

[3] Moron-Villarreyes JA, Soldi C, Amorim AM, Pizzolatti MG, Mendonca AP, D'Oca MGM. Diesel/biodiesel proportion for by-compression ignition engines. Fuel 2007;86:1977-82.

[4] Morrone M, Stuart BJ, McHenry I, Buckley GL. The challenges of biofuels from the perspective of small-scale producers in Ohio. Energy Policy 2009;37:522-30.

[5] Puhan S, Saravanan N, Nagarajan G, Vedaraman N. Effect of biodiesel unsaturated fatty acid on combustion characteristics of a DI compression ignition engine. Biomass Bioenergy 2010;34:1079-88.

[6] Russi D. An integrated assessment of a large-scale biodiesel production in Italy: killing several birds with one stone? Energy Policy 2008;36:1169-80.

[7] Esteban B, Baquero G, Puig R, Riba J-R, Rius A. Is it environmentally advantageous to use vegetable oil directly as biofuel instead of converting it to biodiesel? Biomass Bioenergy 2011;35:1317-27.

[8] Baquero G, Esteban B, Rius A, Riba JR, Puig R. Small-scale production of straight vegetable oil from rapeseed and its use as biofuel in the Spanish territory. Energy Policy 2010;38:189-96. 
[9] Sidibé SS, Blin J, Vaitilingom G, Azoumah Y. Use of crude filtered vegetable oil as a fuel in diesel engines state of the art: literature review. Renew Sust Energy Rev 2010;14:2748-59.

[10] Hossain AK, Davies PA. Plant oils as fuels for compression ignition engines: a technical review and life-cycle analysis. Renew Energy 2010;35:1-13.

[11] Mustafa Ertunc T. Cetane number effect on the energetic and exergetic efficiency of a diesel engine fuelled with biodiesel. Fuel Process Technol 2011;92:1311-21.

[12] Lapuerta M, Villajos M, Agudelo JR, Boehman AL. Key properties and blending strategies of hydrotreated vegetable oil as biofuel for diesel engines. Fuel Process Technol 2011;92: 2406-11.

[13] Lu XC, Zhang WG, Qiao XQ, Huang Z. Fuel design concept for improving the spray characteristics and emissions of diesel engines. Proc Inst Mech Eng D-J Auto Eng 2005;219:547-57.

[14] Suh HK, Roh HG, Lee CS. Spray and combustion characteristics of biodiesel diesel blended fuel in a direct injection common-rail diesel engine. J Eng Gas Turb Power 2008;130:4795-804.

[15] Kegl B. Effects of biodiesel on emissions of a bus diesel engine. Bioresour Technol 2008;99:863-73.

[16] Machacon HTC, Shiga S, Karasawa T, Nakamura H. Performance and emission characteristics of a diesel engine fueled with coconut oil-diesel fuel blend. Biomass Bioenergy 2001;20:63-9.

[17] Blangino E, Riveros AF, Romano SD. Numerical expressions for viscosity, surface tension and density of biodiesel: analysis and experimental validation. Phys Chem Liq 2008;46:527-47.

[18] Selim MYE. Reducing the viscosity of Jojoba Methyl Ester diesel fuel and effects on diesel engine performance and roughness. Energy Convers Manage 2009;50:1781-8.

[19] Totten GE, Westbrook SR, Shah RJ. Fuels and lubricants handbook: technology, properties, performance, and testing, ASTM manual series. West Conshohocken: ASTM International; 2003.

[20] Nwafor OMI. The effect of elevated fuel inlet temperature on performance of diesel engine running on neat vegetable oil at constant speed conditions. Renew Energy 2003;28:171-81.

[21] Misra RD, Murthy MS. Straight vegetable oils usage in a compression ignition engine-a review. Renew Sust Energy Rev 2010;14:3005-13.

[22] Syndi L, Daniel B. Survey of straight vegetable oil composition impact on combustion properties. In: Basu AK, Agarwal AK, Richards P, Thompson GJ, Miers S, Krishnan R, editors. CI engine performance for use with alternative fuels. USA: SAE International; 2009. p. 487-96.

[23] Abolle A, Kouakou L, Planche H. The viscosity of diesel oil and mixtures with straight vegetable oils: palm, cabbage palm, cotton, groundnut, copra and sunflower. Biomass Bioenergy 2009;33:1116-21.

[24] Murayama T, Oh Young-taig, Miyamoto N, Chikahisa T, Takagi N, Itow K. Low carbon flower buildup, low smoke, and efficient diesel operation with vegetable oils by conversion to mono-esters and blending with diesel oils or alcohols. SAE paper no.841161; 1984.

[25] Agarwal D, Agarwal AK. Performance and emissions characteristics of Jatropha oil (preheated and blends) in a direct injection compression ignition engine. Appl Therm Eng 2007;27:2314-23.

[26] Bryan RM. Influence of extended storage on fuel properties of methyl esters prepared from canola, palm, soybean and sunflower oils. Renew Energy 2011;36:1221-6.

[27] Rodenbush CM, Hsieh FH, Viswanath DS. Density and viscosity of vegetable oils. J Am Oil Chem Soc 1999;76:1415-9.

[28] Krisnangkura K, Yimsuwan T, Pairintra R. An empirical approach in predicting biodiesel viscosity at various temperatures. Fuel 2006;85:107-13.

[29] Azian MN, Kamal AAM, Panau F, Ten WK. Viscosity estimation of triacylglycerols and of some vegetable oils, based on their triacylglycerol composition. J Am Oil Chem Soc 2001;78:1001-5.

[30] CAMPSA. Manual de combustibles en la industria. 3rd ed. Madrid: Campsa; 1989.

[31] CEN. EN 590:2004. Automotive fuels - Diesel - Requirements and test methods. Brussels: European Committee for Standardization (CEN); 2005.

[32] CEN. EN 14214:2008. Automotive fuels - Fatty acid methyl esters (FAME) for diesel engines - Requirements and test methods. Brussels: European Committee for Standardization (CEN); 2010.

[33] DIN. DIN 51605. Fuels for vegetable oil compatible combustion engines - fuel from rapeseed oil - requirements and test methods. Berlin: Deutsches Institut für Normung (DIN); 2010.

[34] Ryan TW, Callahan TJ, Dodge LG. Characterization of vegetable oils for use as fuels in diesel engines. In: Proceedings of the international conference on plant and vegetable oils as fuels; 1982 Aug 2-4; Fargo, USA. Saint Joseph: Asae Publication; 1982.

[35] Strayer RC, Craig WK, Zoerb GC. Engine deposit and pour point studies using canola oil as a diesel fuel. In: Proceedings of the international conference on plant and vegetable oils as fuels; 1982 Aug 2-4; Fargo, USA. Saint Joseph: Asae Publication; 1982.

[36] Balat M. Modeling vegetable oil viscosity. Energy Source Part A 2008;30:1856-69.

[37] ISO. ISO 649-2:1981. Laboratory glassware -density hydrometers for general purposes Part 2: test methods and use. Geneva: International Organization for Standardization (ISO); 1982.

[38] ISO. ISO 3105:1994. Glass capillary kinematic viscometers, specifications and operating instructions. Geneva: International Organization for Standardization (ISO); 2006.

[39] Oprea I, Mihaescu L, Prisecaru T, Negreanu GP. Vegetable oil utilization for electricity and heat generation, Proceedings of the WSEAS international conference on renewable energy sources, 2007 Oct 14-16; Arcachon, France.

[40] Marengo E, Longo V, Bobba M, Robotti E, Zerbinati O, Di Martino S. Butene concentration prediction in ethylene/ propylene/1-butene terpolymers by FT-IR spectroscopy through multivariate statistical analysis and artificial neural networks. Talanta 2009;77:1111-9.

[41] Montgomery DC, Peck EA, Geoffrey C. Introduction to linear regression analysis. 3rd ed. New York: John Wiley \& Sons; 2006. 